\title{
Gastric Motility Following Ingestion of a Solid Meal in a Cohort of Adult Asthmatics
}

\author{
Wadu Arachchige Dharshika Lakmali Amarasiri, ${ }^{1 *}$ Arunasalam Pathmeswaran, ${ }^{2}$ Arjuna Priyadharshin de Silva, ${ }^{3}$ Anuradha \\ Supun Dassanayake, ${ }^{4}$ Channa Dhammika Ranasinha ${ }^{4}$ and Hithanadura Janaka de Silva ${ }^{3}$ \\ Departments of ${ }^{1}$ Physiology, ${ }^{2}$ Public Health, ${ }^{3}$ Medicine and ${ }^{4}$ Pharmacology, Faculty of Medicine, University of Kelaniya, Ragama, Sri Lanka
}

\section{Background/Aims}

Asthmatics have abnormal esophageal motility and increased prevalence of gastroesophageal reflux disease (GERD). The contribution of gastric motility is less studied. We studied gastric myoelectrical activity, gastric emptying (GE) and their association with GERD symptoms and vagal function in adult asthmatics.

\section{Methods}

Thirty mild, stable asthmatics and 30 healthy controls underwent real-time ultrasonography and 1 hour pre- and post-prandial cutaneous electrogastrography, following a test meal (480 kcal, 60\% carbohydrate, 20\% protein, 20\% fat and $200 \mathrm{~mL}$ water). The percentage of normal slow waves and arrhythmias, dominant frequency and power, frequency of antral contractions, gastric emptying rate (GER) and antral motility index (MI) was calculated. Twenty-seven asthmatics underwent gastroscopy and in all subjects GERD symptoms were assessed by a validated questionnaire. Vagal function parameters were correlated with gastric motility parameters.

\section{Results}

The asthmatics (37\% male; $34.8 \pm 8.4$ years) and controls (50\% male; $30.9 \pm 7.7$ years) were comparable. None had endoscopic gastric pathological changes. Twenty asthmatics described GERD symptoms. Twenty-two (73.3\%) asthmatics showed a hypervagal response. Compared to controls, asthmatics had delayed GER and lower MI, lower percentage of normal gastric slow waves, more gastric dysrythmias and failed to increase the post-prandial dominant power. There was no correlation of GE and cutaneous electrogastrography parameters with presence of GERD symptoms or with vagal function.

\section{Conclusions}

Asthmatics showed abnormal gastric myoelectrical activity, delayed GE and antral hypomotility in response to a solid meal compared to controls. There was no association with vagal function or GERD symptom status.

\section{(J Neurogastroenterol Motil 2013;19:355-365)}

\section{Key Words}

Asthma; Gastric emptying; Gastroesophageal reflux

\footnotetext{
Received: August 22, 2012 Revised: April 26, 2013 Accepted: April 30, 2013

(c) This is an Open Access article distributed under the terms of the Creative Commons Attribution Non-Commercial License (http://creativecommons. org/licenses/by-nc/3.0) which permits unrestricted non-commercial use, distribution, and reproduction in any medium, provided the original work is properly cited.

${ }^{*}$ Correspondence: Wadu Arachchige Dharshika Lakmali Amarasiri, MD Department of Physiology, Faculty of Medicine, University of Kelaniya, P.O. Box 6, Thalagolla Road, Ragama 11010, Sri Lanka Tel: +94-112958337, Fax: +94-718350683, E-mail: lakmaliamarasiri@gmail.com

Financial support: This study was supported by research grant (Grant No. RG/2004/M/07) from the National Science Foundation of Sri Lanka. Conflicts of interest: None.

Author contributions: All authors contributed towards design, study and writing up of the manuscript.
} 


\section{Introduction}

Gastroesophageal reflux (GER) symptoms are common in patients with asthma and asthmatics are known to have abnormalities in esophageal motility and pathological amounts of GER. ${ }^{1}$ Increased levels of GER predispose to airway disease and delayed gastric emptying (GE) increases GER. ${ }^{1}$

Measurement of gastric emptying is the most common test of gastric motility. The real-time ultrasound method of assessing gastric emptying time is based on measurement of the width of the gastric antrum. Serial antral cross-sectional area is measured after consumption of a test meal at the point where there is simultaneous visualisation of the pyloric antrum, aorta and the superiormesenteric artery. ${ }^{2}$ Ultrasound study of the antropyloric region has been compared to the currently accepted reference method of scintigraphy and to radiography ${ }^{3,4}$ and has been reported to be reliable with good inter-observer agreement. ${ }^{5}$ This method, however, also has disadvantages. It is time-consuming and the technique cannot be performed when it is difficult to visualize the total stomach as a result of excessive air or when the gastric fundus is located behind the costal margin.

Cutaneous electrogastrography (cEGG) is a non-invasive means of recording human gastric myoelectrical activity from cutaneous leads placed on the anterior abdominal wall overlying the stomach $^{6,7}$ and is a reflection of the mechanical activity of gastric smooth muscle. cEGG is recorded one hour pre and post-prandially using a portable EGG recorder. EGG data is analyzed using a software. cEGG can be used to evaluate gastric motor activity and its non invasive nature and easy recording technique makes it an attractive option to study gastric motility. ${ }^{8}$ In humans, gastric electrical activity can be measured by serosal or mucosal electrodes, but their invasive nature limits their use in routine investigations. A good correlation has been shown between cutaneous EGG recordings and myoelectric activity recorded from gastric serosal and mucosal leads. ${ }^{8}$

Many studies have shown the potential role of GER in asthmatics and some patients with gastroesophageal reflux disease (GERD) have delayed GE. It might be logical to assume that delayed GE or abnormal gastric myoelectrical activity (GMEA) is associated with asthma. There have only been 2 previous reports of GE in asthmatics. The first was a scintigraphy GE study on 12 patients with GER-related cough which showed that GE was not delayed. ${ }^{9}$ However, the age of the control group was younger than that of GER-related cough group in the study. The second was a radionuclide study investigating the effect of atropine in 6 asthmatics which demonstrated delayed GE in 2 of the subjects. ${ }^{10}$ Because of the paucity of data, there is a need for further study of gastric motility in asthmatics.

This study describes GMEA and GE of a solid meal in adult asthmatics using electrogastrography and real-time ultrasonography.

\section{Materials and Methods}

Thirty consecutive asthmatics (American Thoracic Society ${ }^{11}$; $12 \%$ improvement and $200 \mathrm{~mL}$ increase in $\mathrm{FEV}_{1}$ following bronchodilator administration) were recruited from medical clinics, irrespective of their GERD symptom status, asthma severity or asthma medication use. Controls were individuals who denied having respiratory symptoms, asthma or other respiratory illness. Being a smoker, alcoholic, diabetic, having an esophageal disease or a history of previous upper gastro-intestinal surgery served as additional exclusion criteria for all subjects.

This study was approved by the Ethics and Scientific Review Committee of the Faculty of Medicine of the University of Kelaniya, Ragama, Sri Lanka.

\section{Vagal Automonic Function and Sympathetic Function}

Vagal autonomic function was assessed by (1) heart rate response to the Valsalva maneuver: sustaining a forced expiration through a mouthpiece connected to a manometer $(40 \mathrm{mmHg})$ lasting 15 seconds, following a deep inspiration; (2) heart rate variation with quiet and deep breathing ( 6 breaths per minute); and (3) heart rate response to standing from supine position.

Sympathetic function was assessed by blood pressure response to standing from supine position. ${ }^{12}$

\section{Gastroesophageal Reflux Disease Symptom Assessment}

Both asthmatics and controls were screened by a validated GERD questionnaire assessing frequency and severity of 7 symptoms on a 5-point Likert scale. A GERD score (sum of the products of frequency and severity of each symptom) was calculated. A cut off score of $\geq 12.5$ was considered as symptom positive for GERD. ${ }^{13}$

\section{Upper Gastrointestinal Endoscopy}

Upper gastrointestinal endoscopy was performed in 27 asth- 
matics that consented, by 2 trained physicians using a fiberoptic endoscope (CLV-U20; Olympus, Tokyo, Japan) and findings graded according to modified Savary-Miller criteria. ${ }^{14}$ Endoscopy was not performed in controls. A patient was given a diagnosis of functional dyspepsia (FD) when structural or acid-related causes for the patient's symptoms were sufficiently ruled out. According to the Rome III criteria, FD is diagnosed when there is no evidence of structural disease (including at upper endoscopy) that is likely to explain the symptoms and if bothersome postprandial fullness, early satiation, epigastric pain and epigastric burning are present for the last 3 months with symptom onset at least 6 months prior to diagnosis. ${ }^{15}$ Of the 30 asthmatics in our study, 10 had endoscopic abnormalities, and 23 had 24 hour $\mathrm{pH}$ abnormalities. Both tests were normal in only three asthmatics. None of these 3 patients had dyspeptic symptoms. Therefore it is unlikely that they had 'FD'.

\section{Gastric Function Tests}

Gastric function tests were performed on consecutive days after an overnight fast of 6 hours. Females were investigated during the proliferative phase of the menstrual cycle. Drugs known to alter gastric motility were discontinued 48 hours prior to the study. ${ }^{16}$ The standard test meal consisted of 4 slices of white bread (90 g), $50 \mathrm{~g}$ dhal cooked in coconut milk and $200 \mathrm{~mL}$ of water (total energy value $480 \mathrm{kcal} ; 58 \mathrm{~g}$ carbohydrate, $21 \mathrm{~g}$ protein, $18 \mathrm{~g}$ fat). ${ }^{17}$ Each subject ingested the test meal within 15 minutes.

\section{Electrogastrography Recording}

EGG was recorded 1 hour pre- and post-prandially using a portable recorder (Digitrapper EGG; Synetics Medical, Stockholm, Sweden) as previously reported. ${ }^{6,16}$ All recordings were made at a sampling frequency of $4 \mathrm{~Hz}$ and low and high cut-off frequencies of 1-18 cpm. The subjects were kept in the supine position, lying comfortably. They were asked to minimize talking or movements during recording to minimize motion artifacts. All electrical appliances that could cause interference with recording were kept well away from the subjects. The electrode area was prepared by abrading the skin with abrasive gel (Omni-Prep) until the skin became pinkish in color. Electrode conductive cream was rubbed into the electrode area, excess cream wiped away and the area allowed to dry prior to placement of the electrodes. In those subjects with excess body hair the abdominal hair was shaved at site for electrodes. The electrodes (disposable, adhesive ECG electrodes) were placed close to the antral region along the antral axis of the stomach. One active electrode was kept on the subject's ventral mid-line, halfway between the xiphoid process and umbilicus. The other active electrode was kept on the subject's left side, $5 \mathrm{~cm}$ distant and $45^{\circ}$ superiorly. The reference electrode was kept on the subject's right side, $5-10 \mathrm{~cm}$ away and at the same level of the middle electrode. Once the subject was in position and connected to the digitrapper, recording was started by pressing the start button. At the end of 60 minutes, the recorder was paused and removed, and the subject was asked to partake of the standard test meal. Following ingestion of the meal, the recorder was re-connected to the electrodes and the recording was continued for another 60 minutes. The start and end of the meal were marked by pressing the 'meal' button. This was done to exclude the meal period from analysis.

The recorded data in the recorder were then uploaded into a computer and analyzed by spectral analysis using a dedicated software program (Electrogastrogram, version 6.40; Synetics Medical). Power spectral analysis uses the Fast Fourier Transform algorithm to extract frequency information of the EGG. Application of Fourier transformation to a time signal results in the generation of a frequency spectrum. Manual visual inspection of the recording was carried out and motion artifacts were removed prior to the analysis.

The following parameters were evaluated before and after the test meal.

(1) Period dominant frequency (PDF): normal PDF was defined as a frequency of between 2-4 cycles per minute.

(2) Percentage of 2-4 cycles per minute normal gastric slow waves

(3) Percentage of gastric dysrhythmias (bradygastrias, tachygastrias and arrhythmias): activity of 0-2 cycles per minute was termed as bradygastria and that of 4-9 cycles per minute as tachygastria.

(4) Period dominant power (PDP)

(5) EGG power ratio (the ratio of the post-prandial PDP to fasting PDP)

(6) Dominant frequency instability coefficient (DFIC)

\section{Measurement of Gastric Emptying and Antral Motility}

Measurement of GE and antral motility was by real-time ultrasonography, using a high resolution real-time scanner (SD550, Aloka, Japan) with a $3.5 \mathrm{MHz}$ curve linear transducer ${ }^{18}$ by the same trained investigator (WADL Amarasiri). All subjects reclined backwards at $45^{\circ}$ to the horizontal plane allowing simul- 
taneous visualization of the antrum, superior mesenteric artery and abdominal aorta (Fig. 1A).

GE was measured as the cross-sectional area of the gastric antrum at fasting and 5, 15,30,60, 90,120, 150, 180, 210 and 240 minutes after ingestion of the test meal (Fig. 1B and 1C). The mean of three readings was calculated at each time during inter-peristaltic relaxation. GE measurement was stopped at 240 minutes, or earlier if fasting gastric antral size resumed and remained unchanged for 30 minutes and there was complete absence of food particles within the antrum. ${ }^{18}$

The following parameters were calculated at each time point.

(1) Gastric emptying rate $=[$ (antral area at 5 minutes - antral area at each time point)/antral area at 5 minutes $] \times 100$

(2) Gastric residual ratio $(\%)=($ antral area at each time point/antral area at 5 minutes $) \times 100$

(3) Antral motility index (MI) = amplitude of antral contractions $\times$ frequency of contractions in one minute.

(4) Amplitude of Contractions $=[$ (maximum antral area at relaxation - minimum antral area at contraction*)/antral area at relaxation] $\times 100\left({ }^{\star}\right.$ Fig. $\left.1 \mathrm{C}\right)$.

(5) Gastric half emptying time $\left(\mathrm{t}_{1 / 2}\right)=$ interval between the end of the meal and the point when antral area was reduced to $50 \%$ of the maximal antral area. ${ }^{19}$

To minimize inconvenience and non-compliance, GE measurement was only carried out for upto 4 hours post-prandial. ${ }^{18}$ Measurements were always taken from the outer profile of the wall as the lumen of the antrum is usually very narrow in fasting subjects and the inner side of the wall is difficult to outline. The mean of three readings was calculated at each time during inter-peristaltic relaxation. The measurements were performed be- tween antral contractions to provide a measure of relaxed width of the antrum. Patients were asked to breathe normally during the measurements to avoid changes in antral diameters related to inspiration and expiration, and to minimize talking. The measurements were performed by the same investigator, who was blinded with respect to the meals. The subjects were examined in a supine position, but between examinations, they were seated. All measurements were at the same time of the day. All females were scanned during the follicular phase of the menstrual cycle. ${ }^{18}$

\section{Sample Size Estimation and Power of Study}

The results on gastric motility presented are from a study that also assessed 24-hour ambulatory esophageal $\mathrm{pH}$ monitoring and gastric emptying in asthmatics. The sample size calculated was the minimum number of subjects required to undergo the invasive esophageal function tests. We calculated that a minimum sample size of 30 in each group would have $90 \%$ power at 0.05 level of significance to detect a mean difference in the total percentage reflux time of 0.66 standard deviation units if the standard deviation of the total percentage reflux time in the asthmatics was taken as 1 unit and the standard deviation in the controls was a third of the standard deviation among asthmatics. The same group of asthmatics and controls underwent gastric emptying studies. $^{20}$

\section{Statistical Methods}

Differences in all electrogastrography parameters (PDF, percentage of 2-4 cpm normal gastric slow waves, percentage of gastric dysrhythmias, PDP, ratio of the post-prandial PDP to fasting PDP and instability coefficients DFIC and DPIC) and
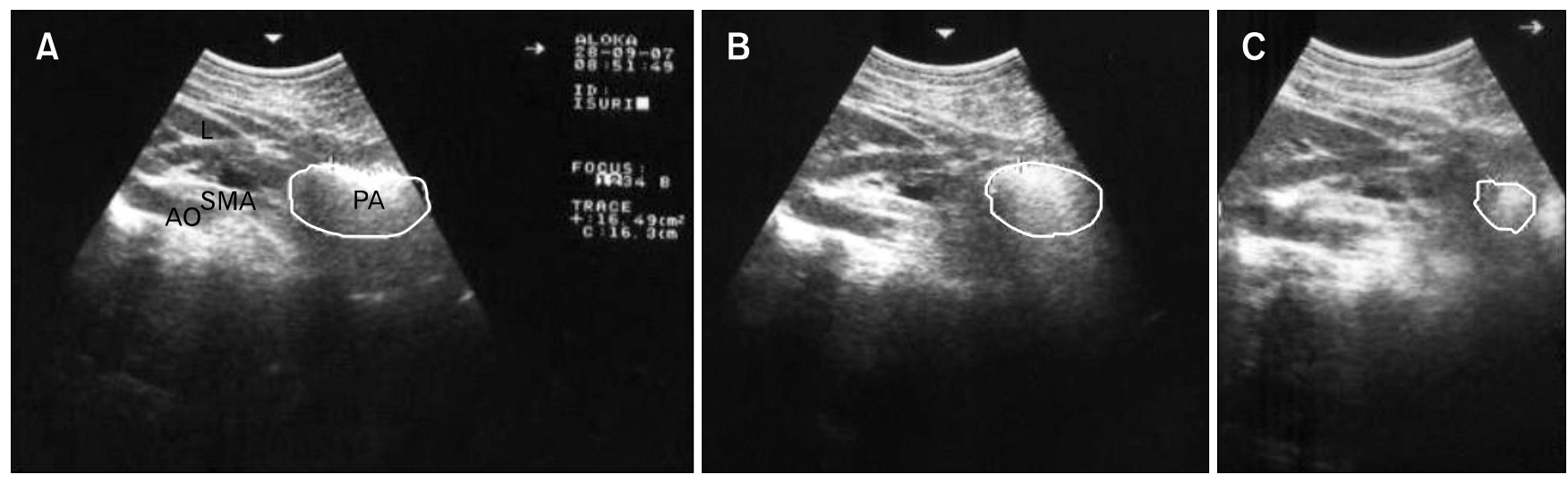

Figure 1. Measurement of gastric emptying and motility using real-time ultrasonography. (A) A scan showing the plane used to obtain the cross-sectional antral areas. (B) A scan showing the antral area at 5 min after ingestion of the test meal. (C) A scan showing the antral area at 210 min after ingestion of the test meal. L, liver; PA, pyloric antrum; SMA, superior mesenteric artery; AO, aorta. 
gastric emptying parameters (gastric emptying rate, gastric residual ratio, $\mathrm{MI}$, amplitude of contractions and $\mathrm{t}_{1 / 2}$ ) between asthmatics and controls were assessed by Mann-Whitney $U$ test. Differences in parameters between controls and asthmatics with and without GERD symptoms were assessed using the Kruskal Wallis test. Wilcoxon rank sum test was used to compare preand post-prandial EGG parameters as the data were found to be not normally distributed. Spearman correlation coefficient was used to assess the association between different variables. Fisher exact test and the Chi-square test were employed to compare categorical variables. A $P$-value $\leq 0.05$ was considered statistically significant.

\section{Results}

Thirty mild, stable asthmatics (11 [37\%] males; $34.8 \pm 8.4$ years) and 30 healthy controls $(15[50 \%]$ males; $30.9 \pm 7.7$ years) completed the study. Asthmatics had a higher frequency and severity of GERD symptoms (Table 1). The autonomic function test results of asthmatics and controls are shown in Table 2 .

Table 2. Cardiovascular Autonomic Function Test Results in Asthmatics and Controls

\begin{tabular}{lccc}
\hline & $\begin{array}{c}\text { Controls } \\
(\mathrm{n}=30)\end{array}$ & $\begin{array}{c}\text { Asthmatics } \\
(\mathrm{n}=30)\end{array}$ & $P$-value \\
\hline $\begin{array}{c}\text { Heart rate variation during deep } \\
\text { breathing (maximum-minimum } \\
\text { heart rate) }\end{array}$ & $20.5 \pm 7.9$ & $30.4 \pm 5.0$ & 0.039 \\
$\begin{array}{c}\text { Immediate heart rate response to } \\
\text { standing (30:15 ratio) }\end{array}$ & $1.1 \pm 0.7$ & $1.2 \pm 0.1<0.001$ \\
$\begin{array}{c}\text { Heart rate response to Valsalva } \\
\text { maneuver (Valsalva ratio) }\end{array}$ & $1.2 \pm 0.2$ & $1.3 \pm 0.2$ & 0.019 \\
$\begin{array}{c}\text { Blood pressure response to standing } \\
\text { (fall in systolic blood pressure) }\end{array}$ & $0.0 \pm 0.0$ & $0.0 \pm 0.0$ & $\mathrm{NS}$ \\
\hline
\end{tabular}

All values are mean $\pm \mathrm{SD}$.

Table 1. Demographic Details of Asthmatics and Controls

\begin{tabular}{|c|c|c|c|c|}
\hline & Controls & $\begin{array}{l}\text { Asthmatics with GERD } \\
\text { symptom scores }<12.5 \\
(\mathrm{n}=10)\end{array}$ & $\begin{array}{l}\text { Asthmatics with GERD } \\
\text { symptom scores } \geq 12.5 \\
(\mathrm{n}=20)\end{array}$ & $\begin{array}{l}\text { All asthmatics } \\
\quad(\mathrm{n}=30)\end{array}$ \\
\hline Age $($ mean $\pm \mathrm{SD}, \mathrm{yr})$ & $30.9 \pm 7.7$ & $35.4 \pm 9.6$ & $34.5 \pm 8.0$ & $34.8 \pm 8.4$ \\
\hline Gender (M:F) & $15: 15$ & $2: 8$ & $9: 11$ & $11: 19$ \\
\hline $\mathrm{BMI}\left(\right.$ mean $\left.\pm \mathrm{SD}, \mathrm{kg} / \mathrm{m}^{2}\right)$ & $21.8 \pm 3.6$ & $20.3 \pm 2.4$ & $21.9 \pm 5.1$ & $21.3 \pm 4.4$ \\
\hline GERD symptom score (mean $\pm \mathrm{SD})$ & $7.6 \pm 0.8$ & $10.0 \pm 1.6$ & $43.1 \pm 17.0^{\mathrm{a}}$ & $32.0 \pm 21.1^{\mathrm{b}}$ \\
\hline \multicolumn{5}{|c|}{ Upper GI endoscopy status, No. of subjects ${ }^{c}$} \\
\hline Normal & & 5 & 12 & 17 \\
\hline Esophagitis, grade 1 & & 2 & 7 & 9 \\
\hline Esophagitis, grade 2 & & - & - & - \\
\hline Esophagitis, grade 3 & & - & 1 & 1 \\
\hline \multicolumn{5}{|l|}{ Severity of asthma, No. of subjects (\%) } \\
\hline Mild intermittent & & $10(100)$ & $16(80)$ & $26(87)$ \\
\hline Mild persistent & & - & $4(20)$ & $4(13)$ \\
\hline \multicolumn{5}{|l|}{ On oral drugs, No. of subjects (\%) } \\
\hline Oral salbutamol & & $6(60)$ & $11(55)$ & $17(57)$ \\
\hline Inhaled salbutamol & & $4(40)$ & $5(25)$ & $9(30)$ \\
\hline Oral theophylline & & $5(50)$ & $6(30)$ & $11(37)$ \\
\hline Oral steroids & & $4(40)$ & $7(35)$ & $11(37)$ \\
\hline Inhaled steroids & & $4(40)$ & $10(50)$ & $14(47)$ \\
\hline \multicolumn{5}{|l|}{ Spirometry results $($ mean $\pm \mathrm{SD})$} \\
\hline $\mathrm{FVC}$ & & $3.2 \pm 0.4$ & $1.3 \pm 0.6$ & $3.2 \pm 0.5$ \\
\hline $\mathrm{FEV}_{1}$ & & $2.7 \pm 0.5$ & $2.7 \pm 0.4$ & $2.7 \pm 0.4$ \\
\hline $\mathrm{FEV}_{1} / \mathrm{FVC} \%$ & & $85.2 \pm 9.5$ & $82.9 \pm 11.0$ & $83.7 \pm 10.4$ \\
\hline
\end{tabular}

GERD, gastroesophageal reflux disease; BMI, body mass index; FVC, forced vital capacity; $\mathrm{FEV}_{1}$, forced expiratory volume in 1 second.

${ }^{\mathrm{a}} P<0.001$, asthmatics with GERD symptom scores $\geq 12.5$ vs. asthmatics with GERD symptom scores $<12.5$; ${ }^{\mathrm{b}} P<0.001$, controls vs. all asthmatics; ${ }^{\mathrm{c}} P<0.05$, comparison of endoscopy categories of asthmatics (e.g., normal vs. Grade I vs. Grade II vs. Grade III using cross tabulation).

None of these patients had macroscopic evidence of gastritis or duodenitis.

All other parameters did not significantly differ between the asthmatics with and without GERD symptoms. 


\section{Electrogastrography Parameters in Asthmatics and Controls}

In Table 3, we compared cutaneous electrogastrography findings between asthmatics and controls. The percentage of normal slow waves among asthmatics was significantly lower than controls both pre and post-prandially. Asthmatics showed more bradygastria in the fasting and more gastric tachygastria in the fed state compared to controls. Controls showed significant increase in PDP post-prandially, but asthmatics failed to do so. Asthmatics had significantly higher DFIC values in both pre and post prandial states than controls. Other EGG parameters did not differ significantly between the 2 groups. On comparison of pre- and post-prandial time periods, there was a significant increase in the mean post-prandial PDF value in asthmatics (pre-prandial 2.6, post-prandial 2.9; $P=0.023$ ), which was not seen in controls (pre-prandial 2.8, post-prandial 2.8; $P=0.988$ ).

\section{Gastric Emptying and Antral Motility in Asthmatics and Controls}

Asthmatics with reflux symptoms had wider fasting antral areas and delayed GE compared to asthmatics with no reflux symptoms (Table 4). The solid GE pattern in all subjects showed the physiologically described bi-phasic pattern. The maximum antral area was reached at a mean time of 10.8 minutes in controls and 11 minutes in asthmatics after ingestion of the meal signifying a brief lag phase. Thereafter, followed a near-linear pattern of reduction in the size of the cross-sectional area, depicting the GE phase. There were significant differences in gastric antral dilation at fasting and 150, 210 and 240 minutes post-prandially between

Table 3. Cutaneous Electrogastrography Parameters in Asthmatics and Healthy Controls

\begin{tabular}{lccc}
\hline & Controls $(\mathrm{n}=30)$ & Asthmatics $(\mathrm{n}=30)$ & $P$-value \\
\hline Pre-prandial (fasting) period (mean $\pm \mathrm{SE})$ & & & \\
Dominant frequency & $2.80 \pm 0.07$ & $2.60 \pm 0.11$ & 0.238 \\
Dominant power & $568.80 \pm 141.80$ & $330.80 \pm 98.00$ & 0.231 \\
$\%$ of normal waves & $94.70 \pm 2.30$ & $88.60 \pm 2.90$ & 0.021 \\
$\%$ of tachygastria & $4.30 \pm 2.20$ & $6.20 \pm 2.20$ & 0.277 \\
\% of bradygastria & $0.90 \pm 0.40$ & $5.08 \pm 1.10$ & 0.001 \\
DFIC & $18.70 \pm 3.10$ & $33.40 \pm 5.20$ & 0.047 \\
Post-prandial period (mean $\pm \mathrm{SE})$ & & 0.587 \\
Dominant frequency & $2.80 \pm 0.09$ & 0.010 \\
Dominant power & $1,180.40 \pm 253.30$ & $630.80 \pm 226.70$ & 0.032 \\
\% of normal waves & $94.60 \pm 0.70$ & $89.50 \pm 1.80$ & 0.019 \\
\% of tachygastria & $1.70 \pm 0.70$ & $6.80 \pm 0.70$ & 0.677 \\
\% of bradygastria & $3.70 \pm 0.80$ & $3.60 \pm 3.90$ & 0.001 \\
DFIC & $17.70 \pm 1.80$ & $33.80 \pm 3.90$ & 0.193 \\
Post/pre EGG power ratio & $1.17 \pm 0.04$ & $1.09 \pm 0.04$ & \\
\hline
\end{tabular}

DFIC, dominant frequency instability coefficient EGG, electrogastrography.

${ }^{a}$ Mann-Whitney U test, asthmatics vs. controls.

Table 4. Gastric Motility Parameters in Response to a Solid Meal in Asthmatics and Healthy Controls

\begin{tabular}{lccrc}
\hline & $\begin{array}{c}\text { Controls } \\
(\mathrm{n}=30)\end{array}$ & $\begin{array}{c}\text { Asthmatics with GERD symptom } \\
\text { scores }<12.5(\mathrm{n}=10)\end{array}$ & $\begin{array}{c}\text { Asthmatics with GERD symptom } \\
\text { scores } \geq 12.5(\mathrm{n}=20)\end{array}$ & $\begin{array}{c}\text { All asthmatics } \\
(\mathrm{n}=30)\end{array}$ \\
\hline FAA $\left(\mathrm{cm}^{2}\right)$ & $2.0 \pm 0.2$ & $1.6 \pm 0.1$ & $2.4 \pm 0.2^{\mathrm{a}}$ & $2.1 \pm 0.2^{\mathrm{b}}$ \\
GER at $210 \min (\%)$ & $71.8 \pm 2.1$ & $85.2 \pm 3.0$ & $70.0 \pm 2.8^{\mathrm{c}}$ & $75.0 \pm 2.2^{\mathrm{d}}$ \\
$\mathrm{t}_{1 / 2}(\mathrm{~min})$ & $119.0 \pm 7.2$ & $147.0 \pm 13.7$ & $115.5 \pm 6.2^{\mathrm{c}}$ & $126.0 \pm 6.6$ \\
Lag time $(\min )$ & $10.8 \pm 2.0$ & $13.5 \pm 5.4$ & $9.7 \pm 2.3$ & $11.0 \pm 2.3$ \\
\hline
\end{tabular}

FAA, fasting antral area; GER, gastric emptying rate; $\mathrm{t}_{1 / 2}$, half emptying time.

${ }^{\mathrm{a}} P<0.01,{ }^{\mathrm{c}} P<0.05$ asthmatics with GERD symptom scores $\geq 12.5$ versus asthmatics with GERD symptom scores $\leq 12.5$. ${ }^{\mathrm{b}} P<0.05$, ${ }^{\mathrm{d}} P<0.01$ controls vs. all asthmatics (Mann-Whitney U test).

Values are mean $\pm \mathrm{SE}$. 
asthmatics and controls (Fig. 2) as well as in MI at 5, 45, 90, 120, 150, 180 and 210 minutes post-prandially (Fig. 3). Fasting antral area was significantly wider and GER was lower in asthmatics with GERD scores $\geq 12.5$ compared to those with lower scores.

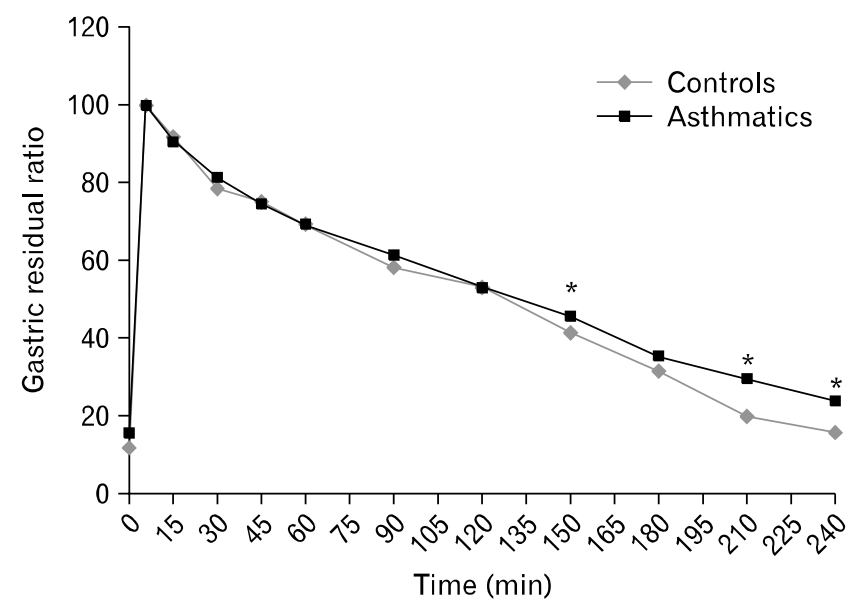

Figure 2. Gastric residual ratios after ingestion of the solid meal in asthmatics and controls. ${ }^{*} P<0.01$ compared with controls (MannWhitney $\mathrm{U}$ test).

\section{Association Between Electrogastrography and Gastric Emptying Parameters}

In the controls, significant positive correlations were observed between MI at 30 minutes and post-prandial PDP increase; gastric emptying rate at 30 minutes $\left(\mathrm{GER}_{30 \mathrm{~min}}\right)$ and per-

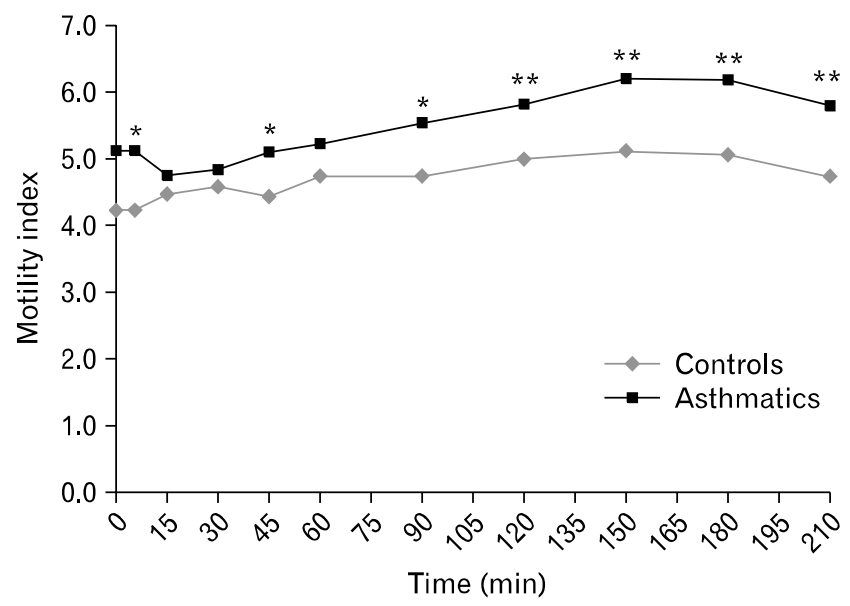

Figure 3. Motility index after ingestion of the solid meal in asthmatics and controls. ${ }^{*} P<0.05$ compared to controls. ${ }^{* *} P<0.01$ compared to controls (Mann-Whitney U test).

Table 5. Correlation of 30-minute Post-prandial Electrogastrography and Solid Gastric Emptying Parameters at 30 Minutes After Ingestion of the Standard Solid Test Meal in Controls $(\mathrm{n}=30)$ and Asthmatics $(\mathrm{n}=30)$

\begin{tabular}{|c|c|c|c|c|}
\hline & \multicolumn{2}{|c|}{ GER at $30 \mathrm{~min}$} & \multicolumn{2}{|c|}{$\mathrm{MI}$ at $30 \mathrm{~min}$} \\
\hline & Correlation coefficient $(r)$ & $P$-value ${ }^{\mathrm{a}}$ & Correlation coefficient $(r)$ & $P$-value ${ }^{\mathrm{a}}$ \\
\hline \multicolumn{5}{|l|}{ Controls } \\
\hline \multicolumn{5}{|l|}{30 min post-prandial period } \\
\hline Dominant frequency & 0.523 & 0.003 & 0.122 & 0.520 \\
\hline Dominant power & 0.086 & 0.653 & 0.459 & 0.011 \\
\hline$\%$ of normal waves & 0.487 & 0.006 & 0.325 & 0.080 \\
\hline$\%$ of tachygastria & -0.173 & 0.359 & 0.004 & 0.984 \\
\hline$\%$ of bradygastria & -0.317 & 0.087 & -0.184 & 0.332 \\
\hline DFIC & -0.445 & 0.014 & -0.268 & 0.152 \\
\hline Post/pre prandial power ratio & -0.237 & 0.207 & -0.111 & 0.559 \\
\hline \multicolumn{5}{|l|}{ Asthmatics } \\
\hline \multicolumn{5}{|l|}{30 min post-prandial period } \\
\hline Dominant frequency & 0.008 & 0.966 & -0.325 & 0.079 \\
\hline Dominant power & 0.067 & 0.725 & 0.155 & 0.415 \\
\hline$\%$ of normal waves & 0.028 & 0.884 & -0.012 & 0.950 \\
\hline$\%$ of tachygastria & 0.005 & 0.981 & -0.106 & 0.578 \\
\hline$\%$ of bradygastria & -0.094 & 0.623 & -0.021 & 0.913 \\
\hline DFIC & 0.022 & 0.909 & -0.177 & 0.349 \\
\hline Post/pre-prandial power ratio & -0.126 & 0.507 & -0.143 & 0.451 \\
\hline
\end{tabular}

${ }^{\mathrm{a}}$ Spearman rank correlation.

GER, gastroesophageal reflux; MI, motility index; DFIC, dominant frequency instability coefficient. 
centage of normal slow waves; and $\mathrm{GER}_{30 \mathrm{~min}}$ and post-prandial PDF. The GER $_{30 \text { min }}$ showed significant negative correlation with the post-prandial DFIC (Table 5). There was no association between EGG and gastric emptying parameters in asthmatics (Table 5).

\section{Correlation With Gastroesophageal Reflux Disease Score}

There was no association between EGG parameters and GERD score. The correlation of $\mathrm{GER}_{210 \mathrm{~min}}$ with the total GERD score just failed to reach statistical significance $(r=-0.388, P=$ 0.056). A significant negative correlation was observed between frequency of regurgitation and $\mathrm{t}_{1 / 2}(r=-0.411, P=0.024)$.

\section{Correlation With Autonomic Function}

On autonomic function testing 22 asthmatics (73.3\%) showed hypervagal response and all showed normal sympathetic response. Each vagal function test parameter was correlated with individual upper gastro-intestinal parameters.

In asthmatics, the post prandial percentage of normal slow waves showed a significant negative correlation with heart rate difference following deep breathing $(r=-3.670, P=0.046)$. Similarly the postprandial percentage of bradygastric waves demonstrated a significant positive correlation with heart rate variation following deep breathing $(r=0.412, P=0.024)$. We could not demonstrate a correlation of the other parameters with the other vagal function tests in asthmatics $(P>0.05$ for all comparisons). There was no correlation between gastric motility tests and autonomic function in controls.

\section{Association With Asthma State}

As all asthmatics were stable mild asthmatics, the effect of asthma severity on the EGG parameter differences was not sought. There was no evidence of association between the type of asthma medication used or whether they used oral or inhaled drugs with the differences between EGG parameters $(P>0.05$ for all comparisons).

\section{Discussion}

This is the first report of GMEA, GE and antral motility in asthmatics using cEGG and real-time ultrasonography. Asthmatics had significant differences in GMEA activity and demonstrated delayed GE compared to healthy controls.

The normal GMEA response after meals is an increase in the percentage of normal slow waves, PDF, PDP, and a decrease in other parameters. $^{21}$

The percentage of 2- to 4-cpm slow waves is a quantitative assessment of the regularity of the gastric slow waves measured from the EGG. This is used to distinguish between normal controls and patients with gastro-intestinal motility disorders as in them the percentage is much lower. In this study, asthmatics had fewer normal gastric slow waves and more bradygastria pre-prandially.

The normal range for the PDF is $2-4 \mathrm{cpm}^{22}$ The PDF decreases from baseline for a short period after eating, then gradually increases. It decreases after a liquid meal and increases after a solid meal. ${ }^{23}$ In the present study, all subjects showed this post-prandial increase in PDF. The post-prandial PDP increase after a solid meal is attributed to stomach distension which reduces the distance to the recording electrodes, and meal-enhanced stomach contraction demonstrated by simultaneous GMEA and GE measurements. ${ }^{9,24}$ A better parameter is the power ratio or relative change of dominant power.

In the present study, in the fed state, asthmatics demonstrated a significant increase in the PDF and failure to increase PDP compared to healthy controls. This failure to increase the power ratio significantly may have contributed to low antral motility in the asthmatics.

Instability coefficients reflect variations of EGG-dominant power and frequency over time. The lower the value of the instability coefficient, more stable is the slow wave. Asthmatics demonstrated significantly higher DFIC compared to controls. Patients with FD and GERD also have been reported to have higher instability coefficients in EGG recordings. ${ }^{25}$

None of the EGG parameters correlated with GERD symptoms scores. However, there was a significant positive correlation between the post-prandial PDP increase and gastric antral motility at 30 minutes after ingesting the same solid meal on consecutive days. The $\mathrm{GER}_{30 \mathrm{~min}}$ also showed significant positive correlation with percentage of normal slow waves, dominant frequency and DFIC. Previous studies have not found a correlation between EGG parameters and GE. ${ }^{26}$ They concluded that as GE is the final coordination of activity of fundus, antrum, pylorus and duodenum and as the EGG reflects only antral activity it is possible that normal EGG parmeters do not guarantee normal GE. ${ }^{27}$ These other studies had either correlated liquid GE to EGG parameters or did not use the values of a similar post-prandial period for comparison. This could have accounted for the lack of correlation reported by them. 
Wide antral areas have been previously reported in patients with GERD and $\mathrm{FD}^{28}$ and have been attributed to impaired antral contractility, increased duodenogastric reflux, increased saliva, delayed GE or insufficient post-prandial accommodation of the proximal stomach. ${ }^{29}$ In the present study, asthmatics had wider antral areas at each time point. It could be that increased gastric secretion following increased vagal activity holds the antral area open. There are no comparative studies in asthmatics, though a study on 25 healthy children and 25 children with GERD showed delayed gastric emptying and a wide antrum after ingestion of test food. ${ }^{30}$

In uncomplicated GERD, antral motility is presumed to be normal. Some studies reported no correlation of epigastric fullness and regurgitation with solid GE. ${ }^{31}$ In our study, asthmatics with higher GERD symptom scores showed reduced GER and antral motility, regurgitation correlating with half emptying time of the solid meal and the total GERD score of significant negative correlation with $\mathrm{GE}_{210 \mathrm{~min}}$. Another study on 12 adults with GERD showed that the area under the emptying time curve was greater, and half and total emptying times were prolonged compared to the healthy subjects. However, no relationship was found between changes in gastric emptying and in the reflux variables. $^{32}$

Theoretically, abnormal gastric motility in patients with GERD and FD could be due to gastritis. However asthmatics in the present study had no evidence of antral gastritis, hence it is unlikely to have had an influence on motility.

A possible role of $\mathrm{GE}$ in the pathogenesis of reflux disease is that, delayed gastric emptying increases the number and duration of reflux episodes. ${ }^{33}$ Increased intragastric volume increases the number of transient lower esophageal sphincter relaxations, and the gastroesophageal pressure gradient and stimulates acid secretion with subsequent increase of the gastric contents available for reflux. $^{34}$

Gastrointestinal motility disturbances have been attributed to alterations in the autonomic nervous system. ${ }^{35}$ Autonomic dysfunction is associated with impaired gastro-intestinal motility in diabetes mellitus ${ }^{36}$ and with functional bowel disorders such as irritable bowel syndrome, functional abdominal pain and non-ulcer dyspepsia. ${ }^{37}$ Our asthmatics had a normal sympathetic response, hence asthma medication was unlikely to have influenced autonomic function and consequently the GE. In asthmatics, the post prandial percentage of normal slow waves showed a significant negative correlation and the postprandial percentage of bradygastric waves demonstrated a significant positive correlation with heart difference following deep breathing. This indicates that vagal hyperreactivity could reduce normal gastric slow waves, increase bradygastria and contribute to abnormal gastric motility. We could not demonstrate a correlation of the other parameters with the other vagal function tests in asthmatics. A similar previous study was not able to show any correlation of gastrointestinal motility parameters with autonomic function. ${ }^{38}$

The asthmatics were mild asthmatics with no other co-morbidities. Whether they had underlying undetected neuropathy was not assessed. Autonomic neuropathy in terms of vagal hypofunction contributes to delayed gastric emptying. However, the asthmatic population in our study showed vagal hyperreactivity. Hence it is unlikely that there was a contribution of vagal function to the delayed gastric emptying. However, the fact that we did not assess for neuropathy is a limitation of the study.

Theoretically, increased vagal activity should increase gastric receptive relaxation and accommodation delaying shifting food to the distal stomach and liquid GE. Though a consequent increase in antral motility and GE of solid food would be expected, it is possible that an increase in gastric acid, gastrin secretion and duodenogastric reflux could cause a reflex decrease in GE, through release of cholecystokinin and secretin. ${ }^{39}$ It would be invaluable to investigate the role of duodenogastric reflux in the pathogenesis of delayed GE in asthmatics.

Several studies have investigated the role of antral motility in gastric emptying. In one study, simultaneous assessment of antral manometry and scintigraphy revealed that antral motility was inversely related to the duration of the lag period in solid gastric emptying and that there was a positive correlation between emptying of solids and antral motility. No significant relation was found between antral motility and overall emptying of the liquid phase of the meal. They highlighted a role of the antrum in the subsequent propulsion of solids and liquids from the stomach. ${ }^{40}$ Another study described that GER and antral MI were significantly lower in patients with functional abdominal pain compared with controls. ${ }^{41}$ Other studies have suggested that although the antrum has a significant role in the emptying of liquids, other undefined factors may modify its effect on gastric emptying. ${ }^{42}$

A rat model has shown that hypoxia inhibits GE and gastric acid secretion, which stimulate gastrin release through a feedback mechanism. ${ }^{43}$ Whether this is a possible mechanism in patients with respiratory disease warrants further study.

Our study has several limitations. First, we attempted to minimize bias due to image distortion in the following ways: by asking the patient to sit still and talk minimally between scans, by re- 
peating the scan at each time point 3 times and by simultaneous measurement by 2 observers. The subjects were not excessively obese and did not have excess amounts of abdominal fat. Despite these precautions, we accept that there would have been some degree of image distortion. This, together with the fact that we had no facility to record the scanning as a continuous process, and were not able to demonstrate intra- and inter-observer agreement are limitations of the study. Helicobacter pylori infection has been found to accelerate $\mathrm{GE}^{44}$ and results in smaller fasting antral volumes. ${ }^{45}$ Other studies, however, have reported no association between GMEA and GE in those with $H$. pylori infection. ${ }^{16} \mathrm{We}$ did not test for $H$. pylori during endoscopy of our asthmatics as there was no macroscopic evidence of gastritis or duodenitis. We admit that this is also a possible limitation of our results. The results reported in this study should, therefore, be confirmed with further well-designed studies using better diagnostic modalities.

In conclusion, the present study demonstrates that asthmatics have significant differences in GMEA, GE and antral motility compared to healthy individuals. The abnormal gastric motility in asthmatics does not seem to be a result of vagal neuropathy, on the contrary it seems to result from a hypervagal response. As delayed GE is seen to provoke reflux, and reflux in turn provokes asthma or asthma-like symptoms, it would be pertinent to treat the gastric pathology to prevent a vicious cycle. Future studies should be directed at examining the role of drugs that improve gastric motility in the management of GERD-related asthma.

\section{Acknowledgements}

The authors acknowledge the assistance provided by technical officers of the Gastroenterology Research Laboratory, Colombo North Teaching Hospital, Sri Lanka. Mrs J Liyanage and Mrs R Subasinghe during the electrogastrography and gastric emptying procedures and Mr. S Abeysundara of the Department of Parasitology, Faculty of Medicine, University of Kelaniya, Sri Lanka for performing microfilarial antigen tests and stool analysis in diagnosis of asthma.

\section{References}

1. Harding SM. Acid reflux and asthma. Curr Opin Pulm Med 2003;9:42-45.

2. Bolondi L, Bortolotti M, Santi V, Calletti T, Gaiani S, Labò G. Measurement of gastric emptying time by real-time ultrasonography. Gastroenterology 1985;89:752-759.

3. Bateman DN, Whittingham TA. Measurement of gastric emptying by real-time ultrasound. Gut 1982;23:524-527.

4. Holt S, Cervantes J, Wilkinson AA, Wallace JH. Measurement of gastric emptying rate in humans by real-time ultrasound. Gastroenterology 1986;90:918-923.

5. Irvine EJ, Tougas G, Lappalainen R, Bathurst NC. Reliability and interobserver variability of ultrasonographic measurement of gastric emptying rate. Dig Dis Sci 1993;38:803-810.

6. Parkman HP, Hasler WL, Barnett JL, Eaker EY; American Motility Society Clinical GI Motility Testing Task Force. Electrogastrography: a document prepared by the gastric section of the American Motility Society Clinical GI Motility Testing Task Force. Neurogastroenterol Motil 2003;15:89-102.

7. Chang FY. Electrogastrography: basic knowledge, recording, processing and its clinical applications. J Gastroenterol Hepatol 2005;20: 502-516.

8. Smout AJ, van der Schee EJ, Grashuis JL. What is measured in electrogastrography? Dig Dis Sci 1980;25:179-187.

9. Kastelik JA, Jackson W, Davies TW, et al. Measurement of gastric emptying in gastroesophageal reflux-related chronic cough. Chest 2002;122:2038-2041.

10. Botts LD, Pingleton SK, Schroeder CE, Robinson RG, Hurwitz A. Prolongation of gastric emptying by aerosolized atropine. Am Rev Respir Dis 1985;131:725-726.

11. American Thoracic Society. Lung function testing: selection of reference values and interpretative strategies. Am Rev Respir Dis 1991; 144:1202-1218.

12. Ewing DJ, Clarke BF. Diagnosis and management of diabetic autonomic neuropathy. Br Med J (Clin Res Ed) 1982;285:916-918.

13. Amarasiri LD, Pathmeswaran A, De Silva AP, Dassanayake AS, Ranasinha CD, De Silva J. Comparison of a composite symptom score assessing both symptom frequency and severity with a score that assesses frequency alone: a preliminary study to develop a practical symptom score to detect gastro-oesophageal reflux disease in a resource-poor setting. Eur J Gastroenterol Hepatol 2010;22:662-668.

14. Standards of Practice Committee, Lichtenstein DR, Cash BD, et al. Role of endoscopy in the management of GERD. Gastrointest Endosc 2007;66:219-224.

15. Drossman DA. The functional gastrointestinal disorders and the Rome III process. Gastroenterology 2006;130:1377-1390

16. Devanarayana NM, de Silva DG, de Silva HJ. Gastric myoelectrical and motor abnormalities in children and adolescents with functional recurrent abdominal pain. J Gastroenterol Hepatol 2008;23:16721677.

17. Wickramanayake TW. Food and Nutrition. In: Wickramanayake LW, ed. Requirements of Energy and Protein. 3rd ed. Colombo: Hector Kobbekaduwa Agrarian Research and Training Institute 1996:30-55

18. Kusunoki H, Haruma K, Hata J, et al. Real-time ultrasonographic assessment of antroduodenal motility after ingestion of solid and liquid meals by patients with functional dyspepsia. J Gastroenterol Hepatol 2000;15:1022-1027.

19. Franke A, Nakchbandi IA, Schneider A, Harder H, Singer MV. The effect of ethanol and alcoholic beverages on gastric emptying of solid meals in humans. Alcohol Alcohol 2005;40:187-193.

20. Gustaffson PM, Kjellman NIM, Tibbling L. Bronchial asthma and acid reflux into the distal and proximal oesophagus. Arch Dis Child 
1990;65:1255-1258.

21. Ferdinandis TG, Dissanayake AS, De Silva HJ. Effects of carbohydrate meals of varying consistency on gastric myoelectrical activity. Singapore Med J 2002;43:579-582.

22. Parkman HP, Harris AD, Krevsky B, Urbain JL, Maurer AH, Fisher RS. Gastroduodenal motility and dysmotility: an update on techniques available for evaluation. Am J Gastroenterol 1995;90: 869-892.

23. Levanon D, Chen JZ. Electrogastrography: its role in managing gastric disorders. J Pediatr Gastroenterol Nutr 1998;27:431-443.

24. Shimada Y, Watanabe M, Shibahara N, Kita T, Itoh T, Terasawa K. Electrogastrographic power ratio in humans is not related to changes in antrum-skin distance but to antral motility. J Gastroenterol 1998;33:310-317.

25. Pfaffenbach B, Adamek RJ, Bartholomäus C, Wegener M. Gastric dysrhythmias and delayed gastric emptying in patients with functional dyspepsia. Dig Dis Sci 1997;42:2094-2099.

26. $\mathrm{Xu} \mathrm{X}$, Wang $\mathrm{Z}$, Hayes J, Chen JD. Is there a one-to-one correlation between gastric emptying of liquids and gastric myoelectrical or motor activity in dogs? Dig Dis Sci 2002;47:365-372.

27. Camilleri M, Hasler WL, Parkman HP, Quigley EM, Soffer E. Measurement of gastrointestinal motility in the GI laboratory. Gastroenterology 1998;115:747-762.

28. Hausken T, Berstad A. Wide gastric antrum in patients with non-ulcer dyspepsia. Effect of cisapride. Scand J Gastroenterol 1992;27: 427-432.

29. Hausken T, Svebak S, Wilhelmsen I, et al. Low vagal tone and antral dysmotility in patients with functional dyspepsia. Psychosom Med 1993;55:12-22.

30. Rico Marí E, Codoñer Franch P, Mollá Olmos E, Calabuig Sánchez M, Ripollés González T. [Gastric emptying in children with gastroesophageal reflux. Evaluation by real time ultrasonography of the pyloric antrum.] An Esp Pediatr 1999;51:33-38. [Spanish]

31. Maddern GJ, Chatterton BE, Collins PJ, Horowitz M, Shearman DJ, Jamieson GG. Solid and liquid gastric emptying in patients with gastro-oesophageal reflux. Br J Surg 1985;72:344-347.

32. Carmagnola S, Fraquelli M, Cantù $\mathrm{P}$, Conte D, Penagini R. Relationship between acceleration of gastric emptying and oesophageal acid exposure in patients with endoscopy-negative gastro-oesophageal reflux disease. Scand J Gastroenterol 2006;41:767-772.
33. Richter JE. Delayed gastric emptying in reflux patients: to be or not to be? Am J Gastroenterol 1997;92:1077-1078.

34. Holloway RH, Hongo M, Berger K, McCallum RW. Gastric distention: a mechanism for postprandial gastro-oesophageal reflux. Gastroenterology 1985;89:779-784.

35. Emmanuel AV, Mason HJ, Kamm MA. Relationship between psychological state and level of activity of extrinsic gut innervations in patients with a functional gut disorder. Gut 2001;49:209-213.

36. Darwiche G, Björgell O, Thorsson O, Almér LO. Correlation between simultaneous scintigraphic and ultrasonographic measurement of gastric emptying in patients with type 1 diabetes mellitus. J Ultrasound Med 2003;22:459-466.

37. Chelimsky G, Boyle JT, Tusing L, Chelimscy TC. Autonomic abnormalities in children with functional abdominal pain: coincidence or etiology? J Pediatr Gastroenterol Nutr 2001;33:47-53.

38. Cunningham KM, Horowitz M, Riddell PS, et al. Relations among autonomic nerve dysfunction, oesophageal motility, and gastric emptying in gastro-oesophageal reflux disease. Gut 1991;32:1436-1440.

39. Konturek SJ, Kwiecien N, Obtulowicz W, Kopp B, Oleksy J, Rovati L. Cholecystokinin in the inhibition of gastric secretion and gastric emptying in humans. Digestion 1990;45:1-8.

40. Camilleri M, Malagelada JR, Brown ML, Becker G, Zinsmeister AR. Relation between antral motility and gastric emptying of solids and liquids in humans. Am J Physiol 1985;249(5 Pt 1):G580- G585.

41. Devanarayana NM, Rajindrajith S, Rthnamalala N, Samaraweera S, Benninga MA. Delayed gastric emptying rates and impaired antral motility in children fulfilling Rome III criteria for functional abdominal pain. Neurogastroenterol Motil 2012;24:420-425, e207.

42. Stemper TJ. Gastric emptying and its relationship to antral contractile activity. Gastroenterology 1975;69:649-653.

43. Yamaji R, Sakamoto M, Miyatake K, Nakano Y. Hypoxia inhibits gastric emptying and gastric acid secretion in conscious rats. J Nutr 1996;126:673-680.

44. Sýkora J, Malán A, Záhlava J, et al. Gastric emptying of solids in children with $H$. pylori-positive and $H$. pylori-negative non-ulcer dyspepsia. J Pediatr Gastroenterol Nutr 2004;39:246-252.

45. Gilja OH, Hausken T, Odegaard S, Berstad A. Three-dimensional ultrasonography of the gastric antrum in patients with functional dyspepsia. Scand J Gastroenterol 1996;31:847-855. 